\title{
Standar Operasional Prosedur Unit Simpan Pinjam Sebagai Upaya Peningkatan Kualitas Pelayanan BUMdes
}

\author{
Much Imron, Subadriyah \\ S-1 Akuntansi, Fakultas Ekonomi dan Bisnis, Universitas Islam Nahdlatul Ulama \\ Korespondensi penulis: subadriyah@unisnu.ac.id
}

\begin{abstract}
Abstrak
Kegiatan pengabdian ini bertujuan untuk membantu permasalahan mitra khususnya BUMDes Tegal Makmur dalam mengelola SOP. Salah satu BUMDes yang telah berjalan cukup baik adalah BUMDes Tegal Sambi Kecamatan Tahunan Jepara. Dimana pada tahun 2017, Badan Usaha Milik Desa (BUMDes) meresmikan Toko Tegal Makmur. Tahun 2017 dikucurkan dana sebesar Rp 60 juta untuk pembangunan fisik toko. Permasalahan yang dihadapi dalam pengelolaan unit usaha BUMDes adalah aspek administrasi, aspek organisasi dan aspek SDM. Solusi yang ditawarkan adalah: 1) program perbaikan dan integrasi administrasi, 2) Program Penguatan Organisasi, 3) Program peningkatan SDM BUMDes. Metode pelaksanaan dilakukan dalam tiga tahap: 1) persiapan, 2) pelaksanaan dan 3) pelaporan. Hasil dari pengabdian ini yaitu SOP yang dijadikan sebagai tujuan pengabdian telah dapat disusun dan digunakan dalam kegiatan usaha mitra. Manfaat SOP juga telah dirasakan oleh mitra.
\end{abstract}

Kata kunci: BUMDes; SOP BUMDes; Kualitas Pelayanan

\begin{abstract}
Community service activities for BUMDes Tegal Makmur in managing SOP. One of the BUMDes that has been running quite well is the BUMDes Tegal Sambi, Annual District of Jepara. Where in 2017, Village-Owned Enterprises (BUMDes) inaugurated the Tegal Makmur Shop. In 2017, Rp60 million was disbursed for the physical construction of the store. Issues discussed in the management unit, BUMDes are administrative aspects, organizational aspects, and HR aspects. The solutions offered are 1) improvement and administration program, 2) Organization Strengthening Program, 3) BUMDes HR Improvement Program. The Implementation Method is carried out in three panes: 1) Preparation, 2) Implementation, and 3) approval. The result of this service is that the SOP which is used as a purpose of service can be developed and used in the business activities of partners. The benefits of SOP have also been felt by partners.
\end{abstract}

Keywords: BUMDes; BUMDes SOP; Service Quality 


\section{PENDAHULUAN}

Mitra dalam pengabdian ini adalah BUMDes di Desa Tegal Sambi Kecamatan Tahunan Kabupaten Jepara. Pada tahun 2017, Badan Usaha Milik Desa (BUMDes) meresmikan Toko Tegal Makmur dengan biaya pembangunan sebesar 60 juta. Menurut Kepala Desa Tegalsambi Agus Santoso. Ada empat tujuan didirikanya BUMDes. Meningkatkan perekonomian desa, meningkatkan pendapatan asli desa, meningkatkan pengelolaan potensi desa sesuai dengan kebutuhan masyarakat, serta menjadi tulang punggung pertumbuhan dan pemerataan ekonomi desa. Toko milik BUMDes sebagai perwujudan dari pengelolaan ekonomi produktivitas desa. Caranya kooperatif, partisipatif, transparansi, akuntabel dan keberlanjutan. Pengelolaan BUMDes diharapkan mampu meningkatkan perekonomian masyarakat. Butuh waktu setahun lebih untuk membangun toko. Pada tahun 2018, setelah bangunan selesai, mendapatkan bantuan dari Kementerian Desa sebesar Rp 50 juta. Dana itu digunakan untuk mengisi barang dagangan toko (Radarkudus.com, 2017).

Permasalahan yang ada pada BUMDes seringkali adalah penguasaan kemampuan manajerial yang kurang memadai. Tak mudah bagi desa mendapatkan seorang yang memiliki kemampuan manajerial unggul dalam hal pengelolaan usaha. Kalaupun ada warga yang memiliki kemampuan seperti itu biasanya sudah bekerja di tempat lain dan kalau dia ditunjuk mengelola BUMDes maka itu hanya sebatas sambilan saja. Akibatnya, BUMDes tidak melaju dan jalan di tempat. Sementara jika menunjuk orang dengan kapasitas yang tidak memadai, ditandai dengan track record yang dimilikinya, maka sama saja dengan membawa BUMDes pada arah yang lebih mengkhawatirkan. Selain itu persoalan administrasi juga menjadi masalah utama pada BUMDes, karena selain laporan harus dipertanggungjawabkan kepada masyarakat terutama kepada BPD (Badan Permusyawaratan Desa).

Permasalahan mitra yang perlu diselesaikan meliputi aspek administrasi. Administrasi pencatatan dan pengelolaan keuangan sudah dilakukan semi komputerisasi. Catatan yang digunakan menggunakan buku catatan secara manual kemudian dimasukkan ke dalam komputer. Hal ini akan menyulitkan pengelola untuk melakukan laporan dan proyeksi. Tanpa proses otomatisasi sistem administrasi, rekapitulasi dan pelaporan membutuhkan waktu yang lama dan kesulitan mengontrol keuangan. Dengan demikian produktivitasnya sangat rendah. Seharusnya waktu untuk menyusun laporan dan rekapitulasi dapat digunakan untuk memberikan pelayanan kepada anggota.

Selain itu permasalahan lain yaitu aspek 
organisasi, dimana mitra telah memiliki $\mathrm{AD} / \mathrm{ART}$, tetapi belum dilaksanakan sebagai mana mestinya. Hal ini karena ketersediaan Standar Operasional Prosedur belum ada. Dalam hal ini pengurus dan pengelola hanya menjalankan pekerjaan sesuai dengan apa yang dipikirkan atau yang dihadapi (bersikap reaktif). Strategi pengembangan belum jelas, dan budaya kerja belum dijalankan secara profesional oleh pengelola BUMDes. Akibatnya adalah efisiensi, produktivitas dan kinerja yang tidak optimal. dengan demikian tata kelola organisasi/ kelembagaan perlu ditata kembali.

Permasalahan yang ketiga meliputi aspek Sumber Daya Manusia BUMDes. Kurangnya ketrampilan pengurus/pengelola dalam pengelolaan unit-unit yang diusahakan oleh BUMDes. Ditunjukkan dari lambatnya peningkatan kinerja BUMDes, pengelolaan bersifat sederhana dan apa adanya, tidak menerapkan manajemen usaha, manajemen keuangan dan sistem akuntansi secara profesional. Upaya meningkatkan pengetahuan dan ketrampilan terkendala oleh SDM dan dana untuk pengembangannya. Untuk ini dibutuhkan edukasi dan sosialisasi yang cukup untuk meningkatkan literasi dan ketrampilan pada masyarakat (Irawati, W., 2019)

Solusi yang ditawarkan sesuai dengan permasalahan prioritas yang disepakati dengan mitra adalah Program perbaikan dan integrasi administrasi. Perlunya pemahaman yang cukup bagi pengurus tentang administrasi keuangan dan perBUMDesan. Penguatan pengelolaan keuangan dengan fasilitasi penguatan administrasi dan pelaporan keuangan. Penguatan administrasi yang dilakukan adalah dengan integrasi administrasi keuangan dan akuntansi dari unit-unit yang dikelola oleh BUMDes.

Program Penguatan Organisasi. Perlunya pemahaman tentang penguatan organisasi kelompok dan pengetahuan tentang penyusunan standar operasional dan manajemen strategi pengembangan organisasi. Dengan adanya SOP dan rencana strategi, maka organisasi mempunyai dasar pijakan aturan kelembagaan yang jelas untuk menjalankan organisasinya.

Program peningkatan SDM BUMDes. pengurus dan pengelola perlu memiliki pengetahuan tentang manajemen BUMDes dalam melakukan pengelolaan terintegrasi di antara berbagai unit usaha yang dikelola. Dengan peningkatan kapasitas SDM dan pemahaman manajemen usaha BUMDes terpadu, diharapkan kinerja pengurus akan meningkat.

\section{METODE}

Pelaksanaan dilaksanakan dalam tiga tahapan, yaitu: 1) tahap persiapan/sosialisasi, 2) tahap pelaksanaan; 3) tahap pelaporan. 
Setiap tahap kegiatan akan melibatkan pengurus, pengelola, anggota dan mahasiswa.

Tahap persiapan meliputi persiapan bagi pengurus/ pengelola/ kader dari masingmasing BUMDes sebagai calon peserta. Selanjutnya persiapan pre-test bagi pengurus/kader. Kegitatan ini bertujuan untuk mengetahui wawasan mendasar tentang organisasi kelembagaan BUMDes, administrasi simpan pinjam dan kewirausahaan, serta kondisi organisasi dari masing-masing kelompok. Persiapan selanjutnya adalah mempersiapkan modul pelatihan dan materi pelatihan yang diperlukan.

Tahapan berikutnya adalah pelaksanaan kegiatan pengabdian, meliputi: sosialisasi terhadap rencana program pengabdian yang akan dilaksanakan dan melakukan koordinasi terhadap evaluasi rencana program, penyuluhan tentang penyusunan SOP dan pendampingan penyusunan SOP.

Dengan adanya dokumen-dokumen ini maka sistem tata kelola manajemen khususnya unit simpan pinjam akan dijalankan sesuai dengan tugas dan fungsi masing-masing bagian. Dengan demikian produktivitas dan pelayanan akan meningkat.

Tahapan beikutnya adalah monitoring dan evaluasi. Kegiatan ini merupakan upaya untuk mengetahui realisasi pelaksanaan kegiatan dengan rencana yang ditetapkan dan untuk mengetahui dampak kegiatan terhadap mitra. Evaluasi akan dilakukan dengan metode wawancara, observasi, dan diskusi triwulanan.

\section{HASIL DAN PEMBAHASAN}

Kegiatan ini dimulai dari penyuluhan penyusunan SOP. Program ini dimaksudkan agar kegiatan BUMDes yang telah dijalankan memiliki operasional prosedur yang standar. Kegiatan penyuluhan ini merupakan kegiatan awal. Kegiatan berikutnya akan dilanjutkan dengan pendampingan penyusuan SOP. Dalam pelaksanaan program ini tim pengabdi melibatkan mahasiswa Kuliah Kerja Nyata (KKN) UNISNU Jepara yang ditempatkan di Desa Tegalsambi. Penyusunan SOP BUMDES pada program pengabdian ini lebih difokuskan pada SOP unit simpan pinjam.

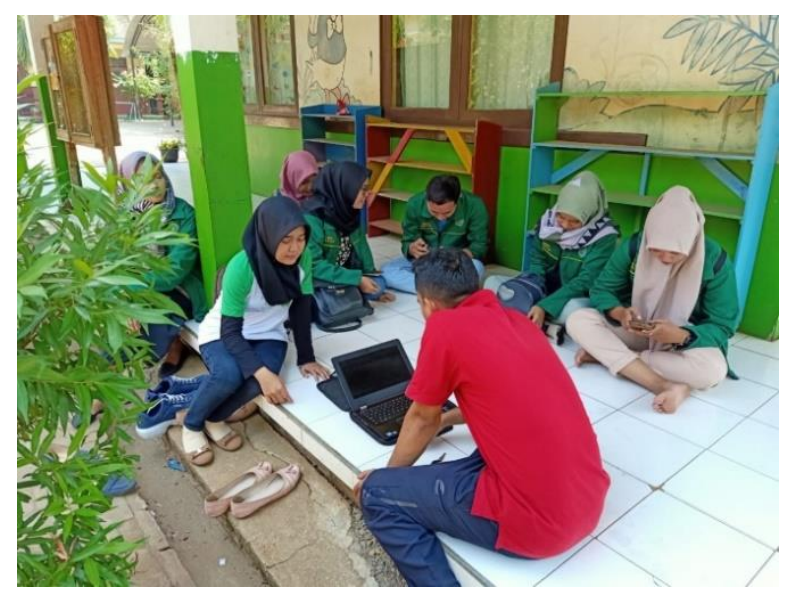

Gambar 1 Penyuluhan penyusunan SOP

Hasil penyusunan Standar Operasional Prosedur (SOP) yang kemudian diterapkan oleh 
BUMDes Tegal Makmur sebagai berikut:

\section{Ketentuan Tentang Simpanan Anggota}

Simpanan Wajib Pinjam (SWP) dan

Resiku Kredit adalah:

- Simpanan Wajib Pinjam adalah simpanan yang wajib dibayar oleh Peminjam dari setiap transaksi pada saat realisasi pinjaman

- Besarnya Simpanan Wajib Pinjam adalah $1 \%$ (satu persen) dari pokok pinjaman dan masuk simpanan anggota.

Resiku Kredit adalah potongan yang wajib dibayar oleh Peminjam dari setiap transaksi pada saat realisasi pinjaman.

Besarnya Resiku Kredhit adalah $2 \%$ (dua persen) dari pokok pinjaman (maksimal plafond Rp 75.000.000,-)

Dibebaskan piutangnya apabila debitur meninggal dunia, piutang yang melebihi plafond akan ditanggung oleh keluarganya

Hal-hal lain yang belum diatur dalam piutang anggota yang meninggal, akan dimusyawarahkan secara kekeluargaan oleh Pengurus dengan keluarganya.

\section{Ketentuan Pinjaman Anggota}

Untuk menjamin ketertiban dan menghindari pelanggaran dalam pemberian pinjaman kepada anggota perlu diatur. Sebagai berikut:

1. Tatacara Pemberian Pinjaman/ Prosedur

\section{Pinjaman.}

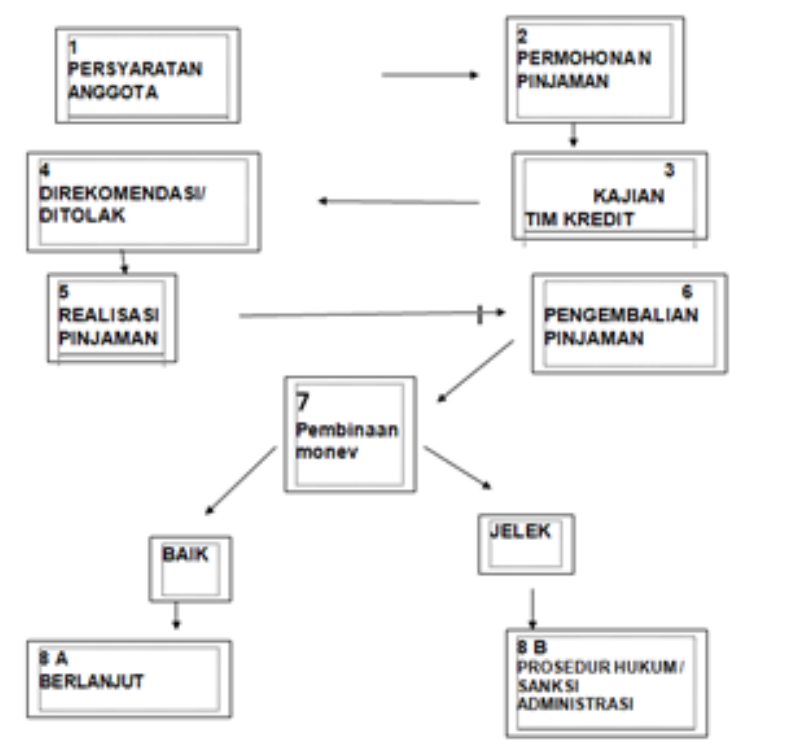

Gambar 2 Prosedur Pinjaman

2. Persyaratan Pinjaman

a. Anggota Unit Simpan Pinjam BUMDES TEGAL MAKMUR Tegal Sambi

b. Telah memiliki rekomendasi dari atasan langsungnya

c. Memiliki karakter dan moral yang baik.

3. Tata cara Pemberian Pinjaman / Prosedur Pinjaman

a. Calon peminjam mengajukan permohonan pinjaman secara tertulis dengan mengisi formulir kepada Pengurus Unit Simpan Pinjam BUMDES TEGAL MAKMUR Tegal Sambi dan melengkapi syarat administrasi / dokumen yang dibutuhkan.

b. Permohonan dicatat pada buku 
administrasi permohonan pinjaman.

c. Permohonan dianalisa secara administrasi / keabsahan dokumennya disertai wawancara singkat mengenai: Tujuan penggunaan pinjaman, gambaran umum bidang usaha yang akan dibiayai tersebut dan kemampuan membayar kembali Anggota calon peminjam serta agunan yang diberikan.

d. Analis Kredit atau Pemutus Kredit menjelaskan kepada calon peminjam mengenai persyaratan dan produk pinjaman/pembiayaan (seperti: maksimal plafond pinjaman, bunga, jangka waktu, dan cara angsuran

e. Petugas memberitahukan hasil rekomendasi dan kekurangan persyaratan kepada calon peminjam.

f. Membuat Perjanjian Hutang dan Penjaminan (jika ada) dan menjelaskan kembali tentang ketentuan pinjaman.

g. Merealisasi Pinjaman, realisasi pinjaman tidak boleh diwakilkan.

h. Membuat Laporan monitoring dan Pembinaan terhadap Anggota dsb.nya

4. Jenis / tujuan pinjaman

a. Konsumtif adalah jenis pinjaman yang akan digunakan untuk memenuhi kebutuhan sehari - hari anggota itu sendiri. b. Komersial adalah jenis pinjaman yang akan digunakan untuk pembelian barang dagangan atau modal kerja.

c. Produktif adalah jenis pinjaman yang digunakan untuk kepentingan pengembangan usaha anggota yang bersifat produksi.

d. Darurat/Kebajikan adalah jenis pinjaman yang akan digunakan untuk memenuhi kebutuhan menesak, bersifat Kebajikan (pertolongan/sosial).

5. Plafon pinjaman Unit Simpan Pinjam (USP)

\begin{tabular}{l} 
Plafon Pinjaman Jangka \\
Pendek maksimal sebesar \\
Angsuran 10 x Jasa $1,5 \%$ \\
sebulan \\
$\begin{array}{l}\text { Plafon Pinjaman Insiden } \\
\text { maksimal sebesar } \\
\text { Angsuran } 5 \text { x Jasa } 1,5 \% \\
\text { sebulan }\end{array}=$ Rp 5.000.000,- \\
\hline
\end{tabular}

Pengurus, Pengawas dan Pengelola tidak diperkenankan meminjam selain menggunakan haknya sebagai Anggota.

6. Jaminan / agunan

a. Segala hak kebendaan Anggota yang berada di Unit Simpan Pinjam BUMDES TEGAL MAKMUR Tegal Sambi menjadi jaminan hutangnya Anggota kepada Unit Simpan Pinjam BUMDES TEGAL MAKMUR Tegal Sambi.

b. Pinjaman Konsumtif dengan jumlah 
pinjaman maksimal $\mathrm{Rp}$ 1.000.000,tidak diperlukan agunan.

c. Pinjaman Komersial dengan jumlah pinjaman Rp. 1.000.000.- s/d Rp 5.000.000,- wajib memberikan agunan berupa surat-surat berharga

d. Pinjaman Produktif dengan jumlah pinjaman Rp. 1.000.000.- s/d Rp 5.000.000,- wajib memberikan agunan berupa surat-surat berharga.

e. Pinjaman Darurat / Kebajikan wajib mendapatkan referen/penjamin dari Ketua Kelompok.

7. Jaminan / agunan

a. Segala hak kebendaan Anggota yang berada di Unit Simpan Pinjam BUMDES TEGAL MAKMUR Tegal Sambi menjadi jaminan hutangnya Anggota kepada Unit Simpan Pinjam BUMDES TEGAL MAKMUR Tegal Sambi

b. Pinjaman Konsumtif dengan jumlah pinjaman maksimal Rp 1.000.000,tidak diperlukan agunan.

c. Pinjaman Komersial dengan jumlah pinjaman Rp. 1.000.000.- s/d Rp 5.000.000,- wajib memberikan agunan berupa surat-surat berharga

d. Pinjaman Produktif dengan jumlah pinjaman Rp. 1.000.000.- s/d Rp 5.000.000,- wajib memberikan agunan berupa surat-surat berharga e. Pinjaman Darurat / Kebajikan wajib mendapatkan referen/penjamin dari Ketua Kelompok

8. Imbalan ( bunga, biaya dll )

a. Imbalan untuk Pinjaman Konsumtif sebesar $\quad 1,5 \%$ flat/tetap setiap bulannya.

b. Imbalan untuk Pinjaman Komersial sebesar $\quad 1,5 \%$ flat/tetap setiap bulannya.

c. Imbalan untuk Pinjaman Produktif sebesar $\quad 1,5 \%$ flat/tetap setiap bulannya jika diangsur bunga dan pokok pinjaman setiap bulannya

d. Imbalan untuk Pinjaman Darurat / Kebajikan 1,5\% flat/tetap setiap bulannya.

e. Biaya administrasi pinjaman $1 \%$ dari pokok pinjaman, dibayar saat realisasi pinjaman.

9. Jangka waktu dan Cara Pengembalian.

a. Jangka waktu Pinjaman Konsumtif minimal 10 bulan dan maksimal 12 bulan.

b. Jangka waktu Pinjaman Komersial minimal 10 bulan dan maksimal 12 bulan.

c. Jangka waktu Pinjaman Produktif minimal 10 bulan dan maksimal 12 bulan.

d. Jangka waktu Pinjaman Darurat maksimal 3 bulan. 
e. Pembayaran Angsuran Pinjaman paling lambat akhir bulan dan dibayarkan di Kantor Koperasi dengan mendapatkan kuitansi pembayaran yang sah.

f. Pembayaran Angsuran Pinjaman Konsumtif dan Komersial terdiri dari Pembayaran Imbalan/Jasa/Bunga dan Pengembalian Pokok Pinjaman.

g. Pinjaman yang diangsur Bunga dan Pokok Pinjamannya setiap periodik jika terjadi keterlambatan pembayaran angsuran, maka akan dikenakan denda $0,5 \%$ dari pokok pinjaman.

10. Hal-hal lain yang belum diatur, akan dimusyawarahkan secara kekeluargaan oleh tim manajemen dengan perwakilan anggota

11. Jika sebelum jangka waktu pinjaman berakhir Anggota ingin melunasi maka bunga/jasa putus

12. Dan sebagainya.

\section{Pinjaman Bermasalah dan Penanganan} Pinjaman Bermasalah

Pengelola wajib mengklasifikasi PDB bermasalah meliputi pinjaman kurang lancar, diragukan dan macet dan melaporkan kepada Pengurus serta Pengawas.

\section{Pinjaman Kurang Lancar}

Pinjaman dapat digolongkan kurang lancar apabila memenuhi kriteria: a. Pengembalian Pinjaman dilakukan dengan Angsuran

1) Terdapat tunggakan angsuran pokok

Melampaui 1 bulan dan belum melampaui 2 bulan, bagi pinjaman dengan masa angsuran kurang dari 1 bulan

2) Terdapat tunggakan bunga

Melampaui 1 bulan tetapi belum melampaui 3 bulan, bagi pinjaman yang masa angsurannya kurang dari 1 bulan

b. Pengembalian Pinjaman Tanpa Angsuran

1) Pinjaman belum jatuh tempo Terdapat tunggakan bunga yang melampaui 3 bulan tetapi belum melampaui 6 bulan atau

2) Pinjaman telah jatuh tempo dan belum dibayar, tetapi belum melampaui 3 bulan.

2. Pinjaman Diragukan

a. Pinjaman masih dapat diselamatkan dan agunannya bernilai sekurangkurangnya 75 persen dari kewajiban hutang peminjam termasuk bunganya atau

b. Pinjaman tidak dapat diselamatkan, tetapi nilai agunannya masih bernilai sekurang - kurangnya $100 \%$ dari kewajiban hutang peminjam 


\section{Pinjaman Macet}

a. Tidak memenuhi kriteria kurang lancar dan diragukan atau

b. Memenuhi kriteria diragukan, tetapi dalam jangka waktu 21 bulan sejak digolongkan sebagai pinjaman diragukan belum ada pelunasan atau usaha penyelamatan pinjaman atau

c. Pinjaman tersebut penyelesaiannya telah diserahkan kepada Pengadilan Negeri atau telah diajukan penggantian ganti rugi kepada perusahaan asuransi kredit.

\section{Pinjaman Berisiko}

Pinjaman berisiko adalah pinjaman yang dilihat dari agunannya ada atau tidak ada, nilai agunan lebih rendah dari Pinjaman.

5. Risiko Pinjaman Bermasalah

Yaitu dengan melihat lancar atau tidaknya pengembalian / angsuran pinjaman. Langkah penyelamatan yang dapat ditempuh pinjaman bermasalah:

a. Penjadualan kembali (reschedulling)/ perubahan syarat pinjaman

1) Prospek Usaha Peminjam

2) Memotivasi Peminjam

3) Analisa Aguna

4) Jadual Ulang Pengembalian Pinjaman

b. Persyaratan kembali (reconditioning)

1) Perubahan Beban Bunga harus dikaji ulang

2) Perubahan Syarat Pinjaman (ada tenggang waktu lagi, untuk mengangsur kembali

3) Tambahan Jaminan / Agunan.

c. Penataan kembali (restructuring)

Dengan melakukan penambahan dana sebagai Investasi atau menambah jumlah pinjaman sebagai Hutang. Dan atau konversi sebagian atau seluruh tunggakan bunga menjadi pokok pinjaman baru atau dihapuskan/dibebaskan.

d. Jumlah Kebutuhan Atas Tambahan Pinjaman

Jumlah kebutuhan atas tambahan pinjaman harus dihitung dan dianalisa agar pinjaman yang macet bisa diselesaikan dahulu.

e. Ketentuan Restructurisasi Pinjaman Perubahan mengenai jumlah pinjaman baru, bunga pinjaman maupun jangka waktu angsuran tambahan jaminan/agunan.

6. Penghapusan Pinjaman

a. Di write off (dikeluarkan dari catatan akuntansi)

b. Dibebaskan dari segala kewajiban hukum

SOP unit simpan pinjam ini diharapkan dapat mengurangi permasalahan-permasalahan yang selama ini muncul karena belum adanya ketentuan yang jelas mengenai simpan pinjam.

Dengan diterapkannya SOP ini, beberapa hal yang dapat diukur adalah 
berkenaan dengan pemenuhan simpanan wajib anggota. Setiap bulan anggota secara tertib telah melakukan penyetoran simpanan anggota karena telah adanya aturan yang jelas. Selain itu adanya SOP ini memberikan pelayanan yang terbaik untuk memfasilitasi kemudahan dalam memenuhi kebutuhan nasabah dengan terus mengupayakan penyelarasan kemampuan, sikap, penampilan, perhatian, tindakan dan tanggung jawab guna mewujudkan kepuasan nasabah agar terbentuknya loyalitas.

Dengan adanya standar operasional yang dikelola dengan baik maka dapat menjalankan, mengarahkan, dan mengawasi kegiatan pelaksanaan pelayanan terhadap karyawan. Sehingga terlaksana pelayanan kepada nasabah dengan aman, lancar, tertib, dan teratur.

\section{KESIMPULAN}

Berdasarkan pembahasan diatas dapat disimpulkan bahwa SOP pada BUMDes merupakan hal penting yang harus diterapkan Adanya pendampingan BUMDes yaitu untuk penguatan proses implementasi konsep dari penyuluhan dan pelatihan yang telah dilakukan, mendampingi BUMDes untuk membenahi penyusunan SOP sebagai peningkatan sistem keuangan dan manajemen internal BUMDes tersebut. Maka, dengan adanya pendampingan tersebut pengelolaan BUMDes diharapkan mampu membaik dan lebih meningkatkan perekonomian masyarakat. Hal ini sejalan dengan PKM (Risal, R., 2020) yang menyatakan Pengetahuan tentang pengelolaan BUMDes dari para pengelola harus terus ditingkatkan untuk kemajuan BUMDes yang dikelola.

SOP yang dijadikan sebagai tujuan pengabdian telah dapat disusun dan digunakan dalam kegiatan usaha mitra. Manfaat SOP juga telah dirasakan oleh mitra.

\section{Saran}

Pelaksanaan kegiatan ini diharapkan tetap dilakukan secara rutin kedepan untuk mengembangkan dan memperoleh SOP yang lebih baik. Beberapa saran yang disampaikan adalah sebagai berikut:

1. Kegiatan yang sudah ada supaya tetap dipertahankan dan ditingkatkan lagi dalam melaksanakannya melalui program pendampingan dan mentoring berkelanjutan.

2. Melakukan kegiatan pendampingan BUMDes dengan topik lanjutan yang berkaitan dengan SOP dan pengembangan BUMDes dengan penyusunan dan pelatihan kepada mitra. 


\section{REFERENSI}

http://BUMDes.id/2018/01/sukseskanBUMDes-dengan-kiat-kiat-berikut. diunduh 11 Januari 2019.

http://sinarharapan.net/2018/10/jokowigunakan-dana-Desa-untuk-kembangkanBUMDes. diunduh 11 Januari 2019.

https://radarkudus.jawapos.com/read/2017/1 2/29/36637/tingkatkan-ekonomi-Desatoko-BUMDes-tegalsambi-diresmikan. diunduh 11 Januari 2019.
Irawati, W., Annisa, D., Aprilia, E. A., Utami, T., \& Angraini, D. (2019). Pengenalan Dasardasar Investasi bagi Ibu-ibu PKK Kelurahan Babakan, Setu, Tangerang Selatan. ABDIMISI, 1(1), 18-23

Risal, R., Wulandari, R., \& Jaurino, J. (2020). Pendampingan Akuntansi Dan Keuangan BUMDes Sedahan Jaya Kecamatan Sukadana Kabupaten Kayong Utara. Cendekia: Jurnal Pengabdian Masyarakat, 2(1), 49-57. 